IZA DP No. 10182

Targeting Tax Relief at Youth Employment

Matthew D. Webb

Casey Warman

Arthur Sweetman

August 2016

Forschungsinstitut

zur Zukunft der Arbeit

Institute for the Study

of Labor 


\title{
Targeting Tax Relief at Youth Employment
}

\author{
Matthew D. Webb \\ Carleton University \\ Casey Warman \\ Dalhousie University \\ and NBER \\ Arthur Sweetman \\ McMaster University \\ and IZA
}

\section{Discussion Paper No. 10182 \\ August 2016}

\author{
IZA \\ P.O. Box 7240 \\ 53072 Bonn \\ Germany \\ Phone: +49-228-3894-0 \\ Fax: +49-228-3894-180 \\ E-mail: iza@iza.org
}

Any opinions expressed here are those of the author(s) and not those of IZA. Research published in this series may include views on policy, but the institute itself takes no institutional policy positions. The IZA research network is committed to the IZA Guiding Principles of Research Integrity.

The Institute for the Study of Labor (IZA) in Bonn is a local and virtual international research center and a place of communication between science, politics and business. IZA is an independent nonprofit organization supported by Deutsche Post Foundation. The center is associated with the University of Bonn and offers a stimulating research environment through its international network, workshops and conferences, data service, project support, research visits and doctoral program. IZA engages in (i) original and internationally competitive research in all fields of labor economics, (ii) development of policy concepts, and (iii) dissemination of research results and concepts to the interested public.

IZA Discussion Papers often represent preliminary work and are circulated to encourage discussion. Citation of such a paper should account for its provisional character. A revised version may be available directly from the author. 


\section{ABSTRACT}

\section{Targeting Tax Relief at Youth Employment ${ }^{*}$}

Canada's Youth Hires program was a targeted employment subsidy that rebated employment insurance premiums to employers with net increases in insurable earnings for youth aged 1824. Using a difference-in-differences approach, in each of two datasets statistically and economically significant employment impacts are observed. Most of the evidence suggests that the 2-2.4 weeks of increased employment resulted from an aggregate reduction in those not in the labour force, with at most a modest change in the unemployment rate. Many estimated effects are larger for males than females. Notably, strong evidence of displacement (substitution away from slightly older non-subsidized workers) is not observed. However, there may be a small reduction in full-time schooling for the targeted group.

JEL Classification: J23, J65, J68

Keywords: youth unemployment, displacement, unemployment insurance, unemployment, targeted tax policy

Corresponding author:

Arthur Sweetman

Department of Economics

McMaster University

1280 Main Street West

Hamilton, Ontario, L8S 4M4

Canada

E-mail: arthur.sweetman@mcmaster.ca

\footnotetext{
* We would like to thank Michele Campolieti, Marco Cozzi, and Allan Gregory for thoughtful comments on a prior draft. Thanks as well to Burt Barnow, Steven Lehrer, James MacKinnon, Harold Henson, and participants at the Canadian Economics Association meetings in Ottawa for helpful comments. Sweetman gratefully acknowledges support from the Social Science and Humanities Research Council of Canada. The analysis was conducted at the Statistics Canada Research Data Centre at Queen's University and we thank Bin Hu for her generous assistance. While the research and analysis are based on data from Statistics Canada, this paper represents the views of the authors and does not necessarily reflect the opinions of Statistics Canada. All errors are our own.
} 


\section{Introduction}

In the wake of recessions governments are interested in stimulating employment with general programs as well as with those targeting particular locations, sectors or demographic groups. While targeted programs have existed for many years, empirical evidence determining their effectiveness for the relevant group, and quantifying unintended consequences such as displacing non-targeted groups from employment is only starting to accumulate. Youth Hires, the Canadian program studied here that subsidized youth employment through an employer side Employment Insurance (EI - called unemployment insurance or UI prior to 1996) premium rebate, is an example of a targeted initiative. In 1999 and 2000 the Youth Hires program rebated any increase in aggregate EI premiums paid by firms for workers aged 18 to 24 that were in excess of the 1998 premiums paid for that age group. Using a difference-in-differences framework, we attempt to determine if there are any impacts on the targeted 18 to 24 year olds, as well as any displacement effects on older age groups for which the targeted group may act as substitute labour.

Canada continues to employ these strategies. One similar program began in 2011 when the federal government introduced a suitably titled Hiring Credit for Small Business that aimed to encourage job creation using an employer side payroll tax reduction for net new employment insured under EI. It was extended in 2012, and then extended again with expanded eligibility in 2013. However, the credit was modest at $\$ 1000$ maximum. $^{1}$

While most economists believe that the relative inelasticity of the labour supply curve implies that changes in payroll taxes are passed on to workers through adjustments in wage rates

\footnotetext{
1 See http://www.cra-arc.gc.ca/hiringcredit/, accessed October 2014. This program is distinct from the Small Business Job Credit that operated in 2014 and 2015. The latter was not a hiring credit; it was based on firm size only and not employment growth; see http://www.cra-arc.gc.ca/whtsnw/tms/sbjc-eng.html, accessed July 2016.
} 
in the long run, with minimal ensuing employment effects, there may be scope for a short-term program to affect employment levels during a period of slack labour demand. ${ }^{2}$ Various papers reviewed in Section 2, and especially Neumark (2013), discuss the economics of these schemes at length, so we do not do so here. However, the central ideas are, first, during periods when unemployment is high, employer (demand) side interventions are more likely than supply side ones to induce employment growth. Second, wage growth is relatively slow during periods of slack labour demand so new programs' short-run causal impacts may be accordingly extended (and larger in magnitude). Finally, from an all-of-government perspective the opportunity cost of hiring credits during recessions may be low if as a result the newly employed reduce their use of EI, social assistance, retraining assistance and/or similar benefits. Of course, "turning off" countercyclical policies can be difficult and allowing such programs to (less- or non-effectively) extend into periods with stronger labour markets may be expensive with little impact.

Overall, our findings suggest discernible impacts of Youth Hires in that it increases employment for the targeted 18-24 age group. Further, we do not find much evidence of displacement of workers in slightly older age groups. Perhaps oddly, much of the effect comes not from reducing aggregate unemployment, but from a reduction in the likelihood of being out of the labor force.

The next section of the paper describes the international evidence for targeted subsidy programs while Section 3 provides the institutional background for the Canadian Youth Hires. Section 4 describes the two independent data sets analyzed, defines two comparison groups that have different strengths and weaknesses, and presents descriptive statistics and an initial

\footnotetext{
${ }^{2}$ Owyang et al. (2013) presents evidence that government spending multipliers are much higher during periods of high, rather than low, unemployment.
} 
graphical analysis. Section 5 outlines the econometric methodology. In particular, we address issues related to inference, which is notoriously difficult in this context where there are few degrees of freedom. (See Imbens and Wooldridge, 2009, esp. sect. 6.5.3; and MacKinnon and Webb, forthcoming.) Section 6 presents the empirical results. Similar findings from both datasets add to our confidence in the analysis. The final section summarizes and interprets the findings.

\section{Relevant Evidence from Other Countries}

Internationally, temporary hiring credits for employers are a common tool when recessionary unemployment is thought to result primarily from deficient labour demand. The Organization for Economic Cooperation and Development (OECD 2010) provides a non-exhaustive international list of such initiatives associated with the recession of 2008-09, and this class of policies has been subject to academic (e.g., Neumark, 2013, Neumark and Grijalva, 2013, Cahuc, Carcillo and Le Barbanchon, 2014), policy (e.g., Bartik and Bishop, 2009), and popular (e.g., Blinder, 2013) attention. Testifying before the US Senate Committee on the Budget, Elmendorf (Congressional Budget Office, 2011) argued that programs, such as Canada's Youth Hires, which subsidize employers as a function of payroll growth have the greatest effects on employment per dollar expended among a range of policies they considered. Employer hiring credits frequently take the form of tax, or social insurance premium, rebates. A recent review of youth focused programs can be found in Bördos, Márton, and Scharle (2015).

Looking first at the US context, the Hiring Incentives to Restore Employment (HIRE) Act of 2010 is one such effort. It exempted employers from paying their share of Social Security taxes for new hires who were unemployed or underemployed. Since in 2012 employers paid 
$6.2 \%$ of each employee's annual earnings below $\$ 110,100$, this amounted to a substantial subsidy. Employers were also eligible for a $\$ 1000$ retention credit for each of those new workers retained for at least one year. Beyond national strategies, Neumark and Grijalva (2013) and Chirinko and Wilson (2010) study various US state-level hiring credits and discuss the implications of alternative program designs. Another US federal employment subsidy, the Empowerment Zone program studied by Busso, Gregory and Kline (2013), is targeted on the basis of geographic "place”. Despite fears that this program would distort economic markets as a result of geographic displacement by firms and workers in response to the subsidy, they find positive benefits with only modest distortions.

Turning next to European comparisons, France initiated a temporary program in 2008 that provided social contribution rebates to small firms hiring low wage workers. Cahuc, Carcillo and Le Barbanchon (2014) observe that the surprise introduction of the credit resulted in effects quite quickly. Importantly, many economists fear that versions of these programs that subsidize all (i.e., gross) new hires, as opposed to net new hires, incentivize distortionary churning as firms let existing workers go in favour of new subsidized workers. However, in France this is not observed; perhaps due to the high level of existing churn. Further, despite the substantial windfall gain to employers Cahuc, Carcillo and Le Barbanchon find that the net cost of the program is about zero once social payment reductions are considered. Focusing on youth unemployment, Sweden's reforms of 2007 and 2009 introduced large payroll tax cuts for youth. Both Skedinger (2014) and Egebark and Kaunitz (2014) find this to have been a very expensive form of employment creation, in large part because it subsidized all employment and not net new employment. A related initiative is the 1997 reduction in Spanish payroll taxes and dismissal 
costs for permanent contract employees examined by Hernanz, Jimeno and Kugler (2003). The authors exploit differences in tax reductions for different age groups. Comparing 20-29 year olds to those aged 30-39, they find significant increases in the probability of being employed amongst the young treated population.

Some argue that the types of studies under discussion should consider general equilibrium effects. Crépon et al. (2013) study a set of randomized experiments in France, which aimed to reduce unemployment among educated youths, and show that there are significant displacement effects which are generally more significant for males than females. Khan and Lehrer (2013) find evidence of displacement effects in a randomized experiment aimed at increasing the size of individuals' social networks. Similarly, Dahlberg and Forslund (2005) observe displacement from wage subsidies and training, exploiting variation across municipalities in Sweden. In contrast, Blundell, et al. (2004) find that displacement effects for the UK's New Deal are either quite small, or counterbalanced by other general equilibrium effects. Understanding the magnitude of any displacement effects is fundamental to the evaluation of labour market interventions, although program design and context appear to matter in ways not yet fully understood.

Targeting is also important. O'Leary, Decker and Wandner (2005) argue that it is required for cost effectiveness. But, this can be problematic if targeting leads to stigmatization as is the case for many US programs that employ vouchers distributed to particular disadvantaged workers. In contrast, the Canadian approach did not require vouchers nor did it target individuals, other than by age, so there was no stigmatization. In fact, subsidized employees need not even 
have been (indeed were probably not in most cases) aware of the program since it operated entirely on the employer side.

\section{Institutional Background Regarding EI and Youth Hires Program}

Legally, the incidence of Canadian EI premiums is partitioned across employers and employees with employers paying 1.4 times the employee rate. Although the system responds to regional unemployment rates, it operates nationally; premiums are set annually by the federal government and are not experience rated for either the employer or the employee. ${ }^{3}$ Youth Hires was announced in the federal budget on February 24, 1998 and was described as being a temporary measure in 1999 and 2000 to address high youth unemployment rates. ${ }^{4}$ Since the premium rebate affected employers in all regions equally, we estimate the impact nationally.

An important limitation to our analysis is the very substantial reform associated with the move from the UI to EI system, which was phased in during the six months ending January 1, 1997. This limits our 'before' period to two years for difference-in-differences analyses, and also limits any ‘falsification' exercises in the pre-program period. One particularly relevant element of the reform for youth is that prior to the reform UI did not cover part-time jobs whereas EI premiums are paid from the first hour of work. ${ }^{5}$ Friesen (2002) finds a modest shift away from part-time, and towards full-time, employment following the move to EI and the associated

\footnotetext{
${ }^{3}$ For a short period starting in 1997, the benefit rate was experience rated on the employee side. It decreased as the number of weeks of benefit receipt in the previous five years increased. Also, in 2013 a quasi-experience rating element was added to the system whereby claimants' job search and new job acceptance criteria were made a function of previous claim history.

${ }^{4}$ Given the time between announcement and implementation, concerns about anticipatory effects are warranted. As seen in Figures 1 thru 3, there is no evidence of anticipatory effect, especially a reduction in employment levels, at the annual level and since the EI "trigger" for payments is annual this is the relevant unit. The online appendix presents plots of seasonally adjusted monthly data which suggest that nothing unusual happened between February and December 1998.

${ }^{5}$ Part time was defined as below both 15 hours per week and an earnings threshold.
} 
introduction of EI premiums for part-time employment. ${ }^{6}$ Also, although it was implemented late in the relevant part of the business cycle, Youth Hires was a post-recession program. Impacts from different phases of the business cycle likely differ.

Unlike the French and American programs, the Canadian one subsidized net (not gross) new insured employment. For workers who were aged 18-24 at any point during each calendar year, any premiums paid by firms in 1999 and 2000 in excess of the 1998 premiums were refunded to the employer. Worker premiums were unaffected. Employer premium rates in 1998, 1999 and 2000 were respectively $3.78 \%, 3.57 \%$ and $3.36 \%$ of insurable earnings with the maximum insurable earnings fixed at $\$ 39,000$ in nominal terms. The declining premium rate implies that a firm's aggregate EI insurable payroll for those in the relevant age group had to, for example, increase by 0.21 percentage points in 1999 before the firm was entitled to the first dollar of rebate. Although the intention of the program was to increase youth employment (and/or reduce unemployment), employers had several margins on which they could adjust to increase premiums paid above the benchmark. They could increase any combination of wages, the number of young workers employed, or hours per year for existing young employees. However, firms received no credit for annual earnings paid to any worker in excess of the maximum insurable. ${ }^{7}$

Importantly, a program that targets a particular identifiable group, in this case youth, may induce substitution towards the subsidized workers (i.e., displacement of close substitutes) and the program's aggregate impact may be less than that experienced by the targeted group. We look for evidence of such effects.

\footnotetext{
${ }^{6}$ Workers with annual earnings below a threshold, who are unable to qualify for benefits, have their share of the premiums refunded through the tax system. However, no such refunds are made to employers.

${ }^{7}$ For more information see Canada Employment Insurance Commission (1999, 2000, 2001).
} 
Success for Youth Hires rested in part on both its salience and transactions costs. If employers are unaware of such a program, then it only operates through easing the budget constraint on expanding firms and not through the behavioral change required to target youth; this also affects the timing of any effect. Clearly, the government was interested in behavioral change since the goal of the program was to target unemployment among a specific age group. Awareness was therefore promoted by mailings to human resource departments in firms paying EI premiums. Additionally, Youth Hires had the advantage of following on the heels of the New Hires Program, which operated in 1997 and $1998 .^{8}$ New Hires’ refund required an application that many small businesses found administratively costly (Canada Employment Insurance Commission, 2000). By contrast, the Youth Hires premium rebate was presented as being automatic and without administrative burden, thereby increasing firms' benefits by reducing transactions costs. Supporting the possibility of a behavioural response by employers, much research documents how workers and firms tailor their behavior to the parameters of the UI/EI system (see, e.g., Green and Riddell (1997); Green and Sargent (1998); Kuhn and Sweetman (1998); Kuhn and Riddell (2010)). Also promoting its success was that the program was sizable. It refunded over $\$ 400$ million in premiums to approximately 295,000 firms (Canada Employment Insurance Commission, 1998 to 2001).

Given the nature of the Youth Hires program, we would not necessarily expect its introduction and termination to have equal and opposing impacts. If firms react to the incentive and hire new young workers, they must incur at least some training and other fixed hiring costs and, therefore, may continue to employ these workers after the rebate period expires. Of course,

${ }^{8}$ The program entitled firms with EI premiums of up to $\$ 60,000$ to a full rebate on additional hires in 1997. It is broadly similar to Youth Hires. Unfortunately, we are unable to examine the New Hires Program due to data limitations. 
job mobility rates are quite high for young workers. Therefore, while any impact may continue beyond the program's horizon it will attenuate over time. In this vein, one group that will need special attention are those who are age 24 in the first year of the program but too old to be subsidized in its second year. We address this group in the empirical specification.

\section{Data and Descriptive Statistics}

We analyze individuals residing in Canadian provinces using the master files of Statistics Canada's Survey of Labour and Income Dynamics (SLID) and Labour Force Survey (LFS). The SLID is a rotating panel that contains roughly 60,000 individuals in each of two overlapping panels starting every three years and lasting for six years. Each individual's annual labour market outcomes are detailed. In contrast, the LFS interviews roughly 54,000 households comprising about 100,000 individuals and capturing labour market information on the week that contains the $15^{\text {th }}$ of each month. For both datasets survey weights are used throughout, and we use all available observations from a reference year. See Appendix A for details.

The bulk of the analysis focuses on 1997-2000, that is, the two years before, and the two years of, the program's existence. As mentioned, the UI to EI reforms make it difficult to use data before 1997, and hiring and training costs suggest the effects of the program are likely to continue beyond its termination. Two comparison groups, with different strengths, are employed. A comparison group close in age will likely compete in the same labour market, which makes it a good/similar comparison group but also makes it susceptible to displacement. A slightly older group is less likely to compete in the same labour markets, and thus is less liable to be displaced, but it is also probably somewhat less similar to the treated group. We use both comparison 
groups at different points in the analysis. The data for analysis are restricted to those aged 18-30, with the initial comparison group aged 25-30. Then a comparison group of individuals 28-30 is used, with those 25-27 regarded as (perhaps negatively) treated. The possibility of including individuals younger than age 18 was not pursued given the very large share in high school.

Any significant impact of Youth Hires could affect variables such as the likelihood of being employed, wages, and/or hours/weeks worked. While government policy may be motivated by unemployed youth who are out of school, post-secondary or high school attendance may also be affected, so we also investigate that outcome. This is similar to analysis on educational decisions in response to changes in the minimum wage, e.g., Landon (1997), Neumark and Wascher (2004), and Campolieti, Fang and Gunderson (2003).

\section{Summary Statistics}

Table 1 contains mean values and sample sizes of dependent variables used in the regression analysis reflecting the variety of outcomes that might be expected to be impacted by Youth Hires. These are presented by age group for the two years prior to, and the two years of, the Youth Hires program. In the upper panel the first three variables are from the SLID and are counts of annual weeks of employment, unemployment and not in the labour force status. These variables are mutually exclusive and sum to the number of weeks in the year. Next are three annual indicator (0/1) variables that are not mutually exclusive. The first is equal to one if the individual was employed at any point in the year, and zero otherwise. The second variable of this set measures the fraction of individuals who were not employed in the year although they sought employment (or were unemployed) at some point in the year. Similarly, the `not in the labour 
force' indicator is set to one if the person is out of the labour market at any point in the year. Total hours worked at all jobs in the year is next, followed by the natural logarithm of total annual income and the hours-weighted average hourly wage across all jobs. Both of the earnings measures are deflated to 1999 dollars. The new job variable indicates whether an individual started with a new employer in the reference year, and the full-time indicator is set to one if an individual's primary job was full-time. If the person was a full-time student at some point in the year the student variable is set to one.

In the lower panel of Table 1, the same statistics are presented for variables from the LFS. All variables in the LFS refer to the reference week. The LFS binary variables for employed, unemployed, and not in the labour force are mutually exclusive and exhaustive. 'Total weekly hours worked' is for all jobs in the reference week, and the hourly wage is for the main job. Weekly income is the product of those two. Both income and wages are converted to 1999 dollars prior to taking the natural log. 'New job' is defined only for those who are currently working and is set to 1 if an individual started a new job in the reference week. Finally, 'student' is a variable which indicates whether the individual was a full-time student in the reference week.

\section{Graphical Analysis}

Plots for three different variables are provided to illustrate the time trend in relevant dependent variables in the years of, and surrounding, the Youth Hires program. For various age groups in the SLID, Figure 1a shows the trends in annual total weeks employed. In the first year of the program, 1999, there are opposite effects for those treated by and those excluded from the program. In 1999 we can see a sharp year over year increase in weeks employed by those aged 
22-24. This contrasts with a slight decline by those $25-27$ and 28-30. At the same time, the weeks worked by those 18-21 increased in line with a trend experienced throughout 1997-2001. The sharp increase for those 22-24, coupled with the slight decline for those 25-27, is what one would expect to see if the program was effective in stimulating employment for the targeted group and simultaneously generating a modest amount of substitution/displacement. In contrast to the effects seen in the first year of the program, there is no obvious jump in the second year.

In Figures $1 \mathrm{~b}$ and 1c, we present the weeks employed trends separately by gender. The increase in the weeks employed in 1999 for the 22-24 age group is much larger for females (Figure 1b) than for males (Figure 1c). The same is true for those aged 18 to 21, but to a lesser extent. Conversely, while there is no decline for females aged 25-27, there is a large decline between 1998 and 1999 for males aged 25-27, suggesting some displacement is potentially occurring for males 25-27.

Weeks not in the labour force, also from the SLID, is presented in Figure 2 and a conceptually similar pattern is evident. Of particular note, especially in the first year of the program, is the increase in weeks not in the labour force for those 25-27 coincident with a decrease in the weeks out of the labour force for those aged 22-24. Recalling that employers were eligible for the credits if they hired those 18-24 in 1999 or 2000, it appears plausible that workers of the younger age group were brought into the labour force in 1999 while those just excluded from (too old for) the program were slightly displaced. Although there may be some ongoing effect, no additional effect is apparent for the second year of the program. ${ }^{9}$

\footnotetext{
${ }^{9}$ In discussions with stakeholders regarding Youth Hires it was suggested that some employers were initially drawn to the rebate, but then realized that the rebate was not sufficient given the productivity differences across the age groups in question. However, this is purely speculative.
} 
Figure 3 uses LFS data to plot the employment rate over time for the various age groups; we see a comparatively large increase in the employment rate for those aged 18-21 in the first year of the program. The other age groups also see increases - though not as large - in their employment rates, which is to be expected as general economic conditions were improving.

Although we do not want to draw too many conclusions at this stage of the analysis, these graphs support the idea that employers were preferentially hiring those subsidized by the program. Moreover, the magnitude of the aggregate affect is modest in all three graphs. Clearly, there are a large number of employers who are increasing the size of their workforce as a result of macroeconomic trends and for whom this rebate is a windfall gain.

\section{Econometric Approach}

We employ a framework that, in terms of the equations estimated, is similar to a linear difference-in-differences (DiD) specification. However, the results do not have the usual interpretation as the causal impact of the treatment on the treated. Both theory and the graphical analysis suggest that the common trend assumption required to identify such a parameter is not satisfied (see, e.g., DiNardo and Lee, 2011) given that the program potentially has both direct causal impacts on the targeted age groups, and indirect causal impacts on slightly older workers. That is, it seems plausible that the 25 to 30 age group, which is too old for Youth Hires, is displaced by the program. In this situation, the DiD coefficient can be interpreted as the change in the gap between the treatment and comparison groups across the policy periods, and not as the impact of the policy change on the treatment group with the comparison group unaffected. 
Beyond identification, inference using a DiD specification with a policy change at the aggregate level can be problematic as demonstrated by Bertrand, Duflo and Mullainathan (2004). The policy we are investigating occurred at the national level, but may have had differential impacts for individuals born within different birth years. For this reason we cluster our standard errors by birth year, which results in 16 clusters. However, the cluster-robust variance estimator yields unreliable inference when there is a small number of clusters. In the presence of few clusters, Cameron, Gelbach, and Miller (2008 - CGM hereafter) argue that the wild cluster bootstrap-t technique works well and we employ this approach. ${ }^{10}$ Since there are relatively few examples in the literature comparing these methods in application, we initially explore alternative approaches to inference, such as different distributional assumptions for t-statistics, and observe some variation. However, for the vast majority of the analysis we present only results from our preferred method of inference, which is to generate bootstrap p-values using the wild cluster bootstrap-t technique with the null hypothesis that the coefficient of interest equals zero imposed. ${ }^{11}$

The first specification we estimate employs data from 1997-2000 and regards those aged 18-24 as the treated group, and those aged 25-30 as the comparison group, as specified:

$$
Y_{i t}=\beta_{0}+\beta_{Y H} Y H_{i t}+\beta_{99} \text { Only1999 }_{i t}+\beta_{A} \text { Age }_{i t}+\beta_{B} \text { YearBorn }_{i t}+\beta_{Y} \text { Year }_{t}+\left[\beta_{C} \text { Controls }_{i t}\right]+e_{i t} .
$$

Where $\mathrm{Y}_{\text {it }}$ represents a labour market variable of interest; $Y H$ is the Youth Hires indicator which is set to one if individual $i$ is of an age targeted by the program in a year, $t$, when it is operating;

\footnotetext{
${ }^{10}$ Of particular importance when the number of clusters/observations is small, the t-statistic has the advantage of being asymptotically pivotal (i.e., its asymptotic distribution does not depend on unknown parameters), which allows for asymptotic refinement (i.e., faster convergence to the relevant test size). Also, Davidson and MacKinnon (1999) argue for imposing the null hypothesis, which can provide additional refinement if the test statistic and bootstrap data generating process are asymptotically independent. This procedure is extended for 12 or fewer clusters in Webb (2014), and argued for in the case of unbalanced clusters in MacKinnon \& Webb (forthcoming).

11 We thank Cameron, Gelbach and Miller for making their code available.
} 
and Only1999 is an indicator set equal to one for individuals who qualify for the subsidy in the first year of the program, but not the second. Age, YearBorn and Year are all vectors comprising full sets of indicator variables that respectively represent the individual's age (measured in years as of year $t$ ) and birth year, and the calendar year in question. This represents an effort to flexibly control for any background effects that may influence the coefficient of interest. The vector of variables identified as Controls are in brackets to indicate they are included in some, but not all, specifications. For both datasets the control variables are an indicator for gender, indicators for province of residence, an indicator for urban residence, an indicator for married, and an indicator for high school graduation. The SLID regressions additionally include indicators for various ethnicities and an indicator for immigrant status. The monthly nature of LFS, allows for the inclusion of a full set of months indicators. The $\beta$ s are vectors of coefficients to be estimated.

In all cases, the equations are estimated using ordinary least squares (OLS). Some specifications are linear probability models. Standard errors are clustered on the individual's birth year since we view the program as having differing impacts across cohorts. This approach allows $e_{\text {it }}$ to be arbitrarily correlated within clusters, but assumes zero correlation across birth cohorts. In some specifications employing the SLID data, an individual fixed effect is included recognizing that individuals are in the sample for up to four years.

The coefficient $\beta_{\mathrm{YH}}$ is the DiD variable of interest and, as mentioned, its estimate will conflate any positive impact on those in the treatment group with any negative impact on those in the comparison group in the years when the program is operating. We are agnostic as to the expected sign of $\beta_{99}$ since it will hinge on the impact of the program in 1999 and the degree of labour market attachment in the subsequent year. We do not report the coefficients for $\beta_{99}$ in the 
text, though in general, the coefficients are of the same sign, smaller in magnitude and of lesser statistical significance than the coefficients for $\beta_{\mathrm{YH}}$.

A second specification is estimated using the 28-30 age group as the comparison group. Plausibly, this comparison group is less (or is minimally) affected by the Youth Hires program, so treatment effects can be estimated separately for the targeted and potentially displaced groups. However, it is less credible that this older age group would have a similar trajectory across time as that of the treated age groups in the absence of the policy change. That is, the common trend assumption is less credible given the larger gap in age and the well-known differences across the business cycle in rates of unemployment, job turnover, and the like with age. An attempt was made to conduct a three period analysis of the program, with the aim of determining the outcomes of the targeted group before, during and after the program. However, this was frustrated by the lack of a clear comparison group in the "after" period. Individuals treated in 1999 and 2000 would be 20-26 years old in 2002, but that age range would consist of both treated and untreated individuals in the year 2000.

To test the robustness of our research design, we conduct a series of falsification exercises using data from 2002 to $2005 .{ }^{12}$ It would be preferable to conduct a falsification exercise using a period prior to the program but, unfortunately, significant EI reforms in 19961997 render this infeasible.

\footnotetext{
12 This time period leaves a two-year gap after the end of the program in case there are any "knock on" effects, without extending too far from the policy change given the possibility of other age-specific changes derived from the education system. See DiNardo and Lee (2011) regarding the benefits of falsification tests.
} 


\section{Regression Analysis}

Table 2 compares various approaches to inference for equation (1) using three key dependent variables - all measures of employment. The first two regressions use SLID data, and the third uses LFS data. For each dependent variable there are two OLS specifications, one with a minimal set of covariates and the other with a full set of controls. For the data from the SLID, there is also a specification including both individual fixed effects and a full set of controls. The regression with minimal controls is, we believe, closely aligned with the central policy question, which is unconditional: What is the effect of the age-specific population-level policy change on, primarily, employment and, secondarily, other dependent variables? Regressors are subsequently added to enrich the interpretation by allowing conditional influences to be observed and, especially, the analysis is extended to explore important gender-related heterogeneity. In all cases, but particularly for the OLS regressions which are less time-consuming to bootstrap, a large number of bootstrap replications are employed to increase the precision of the estimated pvalues.

\section{Comparison Group Aged 25-30}

Coefficients are presented in the first line of Table 2 and, in a key result, all show sensible modest increases among the targeted group relative to the slightly older one associated with the program. Weeks of employment increased by approximately 2-2.5 weeks a year, and the probability of employment increased by $3.5 \%$ to $4 \%$ as measured in the SLID or just over $1 \%$ as measured in the LFS. Turning to the alternative approaches to inference, the heteroskedasticity robust p-values in the SLID are large relative to those obtained using Stata's 'cluster' command. 
Given the 16 clusters in this analysis, the degrees of freedom adjustment makes a modest difference with more conservative choices having p-values close to those from bootstrapping.

Two implementations of the wild cluster bootstrap-t are also undertaken - the first without, and the second with, the null hypothesis that the coefficient of interest is zero imposed. The procedures use t-statistics for inference, where the bootstrap t-statistics are estimated using cluster robust standard errors. Each estimated t-statistic for the full dataset is compared to an empirical distribution of t-statistics generated by the wild cluster bootstrap to produce a p-value; see CGM for details. For the OLS models, the p-values increase slightly, but still mostly indicate statistical significance at conventional levels. For the fixed effect model, the p-values actually decrease slightly. In accord with the evidence in CGM, and Davidson and MacKinnon (1999), we take the wild bootstrap with the null imposed as our preferred approach to inference. It is reassuring, however, to see that there are not excessive differences in inference across the last 3 approaches, which are arguably superior to the others. In fact, and very surprisingly, none of the approaches suggest dramatically different inferences. However, the clustered approaches with a large number of degrees of freedom appear to have p-values that are too small and those for the heteroskedastic version appear to be too large if more conservative degrees of freedom adjustments are made. We observe similar patterns for the other dependent variables, although to save space we do not present these results.

In terms of the substantive results, they almost everywhere indicate statistical significance at conventional levels. In fact, the p-values for the optimal approach are quite similar for the LFS and two sets of SLID coefficients. This provides robust evidence - based on alternative approaches to inference and three variables from two datasets - that Youth Hires had 
a causal effect increasing employment for the targeted age group relative to those slightly older. Nevertheless, the estimate is near the margin of what can be detected in these data.

Results from the specification in equation (1) for a range of relevant dependent variables using 25-30 year olds as a comparison group are presented in Table 3. The upper panel presents results from the SLID, while results from the LFS are presented in the lower panel. Among the dependent variables from each dataset, those at the top of each panel are alternative measures related to employment, unemployment and out of the labour market status. The SLID provides two measures of each, whereas the LFS only has one. Employment is the only variable for which there is a strong prior expectation regarding the sign of the coefficient if the program is functioning as intended. Although some might also have expected unemployment to decrease, it is well known by labour economists that, especially following a recession, some of those classified as out of the labour market desire employment and are out of the labour force only because they ceased searching for a job. As jobs become available individuals may shift from out of the labour market to employment or unemployment.

The dependent variables in the lower half of each panel represent ancillary features of the labour market that may be affected by the policy change, but we are agnostic regarding the expected sign of the coefficients since theory suggests that there might be opposing effects in operation. For example, average hours of work could increase if any additional employment results from increasing the hours of part-time workers, or could decrease if additional low hours part-time youth are added to the labour force. In line with impacts from changes to minimumwage legislation, the additional opportunities for employment could potentially draw youth out 
of school so that the percentage of full-time students might decline. These dependent variables are included to improve our understanding of the program's impacts.

The equations estimated in this table are for the relevant population first, and then separately by gender. The latter highlights an interesting finding. Essentially none of the coefficients, in either dataset, is statistically significant for females for this 25-30 year old comparison group (although compare to Table $4 \mathrm{~b}$, discussed below). The entire policy response to the Youth Hires program appears to be concentrated among males. Or, alternatively, the response is more muted for females and thus statistically insignificant.

Looking first at the coefficient estimates in the upper half of the table for each dataset, the positive effect on employment seen in Table 2 is repeated in Table $3 .{ }^{13}$ Moreover, both datasets are consistent in finding that there is no statistically significant change in the unemployment rate associated with the program; rather, there is a reduction in the various measures of 'not in the labour force'. The LFS evidence is not as compelling. Although there appears to be some reduction in out of the labour force, the impact on employment is only statistically significant at the $11 \%$ level in Table 3 . This contrasts to the $9 \%$ level of significance for the same regression in Table 2 with more bootstraps and more precise p-values, and the $6 \%$ level seen in Table 2 in the model without statistical controls - with the latter also having a larger point estimate. Overall, we take the evidence as suggesting that the program increased the relative employment rate of the targeted group compared to those slightly older, with youth simultaneously drawn into the labour force so that unemployment remained relatively stable. It also illustrates the variability of standard error estimates.

13 The coefficients in the employment regressions in Tables 2 and 3 are identical. Differences in the p-values result from the Table 2 using 9999 bootstraps, while Table 3 uses 1499 and is less precise. 
Average hours of work per worker are not statistically significantly affected by the policy change in either dataset, and the estimated coefficients are of opposite signs across the datasets. Wages and/or annual earnings also appear to be largely unaffected, although the point estimates are mostly negative and one of them is statistically significant. Similarly, the results are mixed for the incidence of new jobs, but there appears to be a small decrease in the LFS, and also a small decrease in the incidence of full-time employment for youth. Finally, there is no evidence that this policy change is inducing students to leave their studies using this comparison group.

\section{Comparison Group Aged 28-30}

Those aged 28-30 serve as the comparison group in the regressions in Tables $4 \mathrm{a}$ and $4 \mathrm{~b}$ and they are compared not only to those subsidized by the premium rebate, but also to those aged 25-27 who are slightly too old to qualify. Further, those 18-24 are subdivided into two smaller age groups to highlight any patterns with age. We also present the estimates separately by gender. The very first row looking at annual weeks employed in the SLID, tells an interesting story. Relative to the 28-30 age group, two treated age groups for each sex (not only males as in Table 3) have point estimates that show appreciable relative increases in their weeks of work, with the coefficient for the youngest group being statistically significant for both males and females while the coefficient for the 22 to 24 year olds is only statistical significant for females. In contrast, the coefficients for the age group just outside the age cutoff for the EI premium rebate are not large in magnitude (negative for males and positive for females) and are not statistically significant. For the LFS, the coefficients on employment tell the same story, but both coefficients for the policy affected age groups are statistically significant for both sexes. Again, no evidence of 
spillovers/displacement is observed. Although the coefficients change somewhat from Table 3, those on labour force status variables largely support an interpretation suggesting that the policy change increased employment among the targeted age groups. In terms of the magnitude of the effects, they are appreciable, but not enormous, which accords with the magnitude of the subsidy associated with Youth Hires. They are also near the limits of detection with the small number of age groups (degrees of freedom) available.

By breaking the subsidy-eligible group into an older and younger half, Tables 4a and 4b also make obvious the finding that the effects of the program appear to be larger for the 18-21 age group than the 22-24 one, which differs slightly from the informal graphical analysis. Also, some of the coefficients in the bottom half of each dataset's panel that are not statistically significant in Table 3 are significant in Tables $4 \mathrm{a}$ and $4 \mathrm{~b}$. In particular, there is some evidence in this specification that students were drawn out of school as a result of the subsidy to employment targeted at their age group.

Given that the coefficients on the 25 to 27-year-old group are almost never statistically significant, and their signs differ between males and females, the best interpretation may be that situations where the impact under study is close to the minimum detectable effect require great care to ensure that we are modeling the data generating process and not the idiosyncrasies of the data. The differences between Table 3 and Tables $4 \mathrm{a}$ and $4 \mathrm{~b}$ highlight the need for sensitivity analysis employing alternative specifications. Inference also needs to be conducted carefully. Nevertheless, we believe that the weight of evidence across these two independent datasets and various specifications supports a modest but statistically significant impact of the program with relatively little spillover. 


\section{Falsification Tests}

The timing of the data for the falsification tests presented in Table 5 is not ideal, especially since there was an expansion to the EI maternity and parental leave benefits in 2001 that may have affected our age groups differentially. Nevertheless, the results provide some support for the analysis. Of the 63 regression coefficients estimated, seven (or 11\%) of them are statistically significant at the $10 \%$ level, with most of these being significant between $5 \%$ and $10 \%$. This is well within the range of what one would expect given the level of the test. ${ }^{14}$ Importantly, all of the employment related coefficients have point estimates very close to zero and none of them is statistically significant. Also, the significant coefficients in Table 5 do not accord with a pattern that is easy to interpret as being consistent with an alternative interpretation of the program impacts. Overall, there does not appear to be evidence to undermine the conclusions in this analysis.

\section{Discussion and Conclusion}

We examine the effectiveness of a Canadian stimulus program designed to temporarily combat high youth unemployment. The Youth Hires program subsidized employers to hire youth between the ages of 18 and 24 by rebating EI premiums for net new insured employment. Overall, we believe the evidence supports the conclusion that this program served to increase weeks employed among the subsidized population by about one or two weeks per year on average, or employment rates by $3.5 \%-4.4 \%$, relative to older individuals. Interestingly, it

\footnotetext{
${ }^{14}$ Of course, it also reminds us that results in the earlier tables are subject to both type I and type II errors; although the earlier tables have, proportionately, far more coefficients that are statistically significant and typically with smaller p-values.
} 
appears that the effect of the program was predominantly experienced by males. The impact of female employment depends on the specification of the comparison group. In interpreting these results it is worth remembering that the value of the annual rebate for net youth nominal earnings growth was around 3.5\% of total insurable earnings (i.e., below $\$ 39,000$ per worker/year). A substantial percentage of the total subsidy payment can be thought of as a windfall gain for employers who were expanding in any event.

A key issue relevant to our interpretation is that the business cycle pattern of the variables under study may differ across age groups thereby confounding our findings. If this is the case, then our estimates for employment may be biased up and those for unemployment biased down. To alleviate this concern we restrict our sample to very similar age groups. Also, the fact the unemployment does not appear to be affected by the policy suggests, in our view, that such biases are probably not extreme since our expectation is that both the policy and any biases would tend to decrease unemployment.

Despite fears regarding displacement, little evidence of such effects are observed in this analysis. However, if displacement effects were, say, on the order of 20 or $30 \%$ of the magnitude of the main effects, then it is unlikely that they would be statistically significant in these data. In some ways our results may be similar to those found by Busso, Gregory and Kline (2013). There may be some distortion resulting from the policy, but if there is then it is small and does not overturn the intended impact of the program. Nevertheless, considering substitution/displacement is important since they are trade-offs ubiquitous in social policy development, especially when programs seek to assist targeted groups. Of course, a partial equilibrium analysis such as this cannot answer the broader general equilibrium question about 
the number of jobs produced in, or the benefits accruing to, the economy as a whole as a result of the program. 


\section{References}

Angrist, J.D., and J.S. Pischke. 2008. Mostly Harmless Econometrics: An Empiricist's Companion. $1^{\text {st }}$ ed. Princeton University Press.

Bartik, T.J., and J.H. Bishop. 2009. "The Job Creation Tax Credit: Dismal Projections for Employment Call for a Quick, Efficient, and Effective Response.” Economic Policy Institute Briefing Paper.

Bertrand, M., E. Duo, and S. Mullainathan. 2004. "How Much Should We Trust Differences-indifferences Estimates?” The Quarterly Journal of Economics 119 (1): 249-75.

Blinder, A. 2013. "Fiscal Fixes for the Jobless Recovery.” Accessed March 2016. Wall Street Journal.

Bördos, Katalin, Márton Csillag, and Ágota Scharle. 2015. "What Works in Wage Subsidies for Young People: A Review of Issues, Theory, Policies and Evidence." International Labour Office - EMPLOYMENT Working Paper 199.

Busso, M., J. Gregory, and P. Kline. 2013. "Assessing the Incidence and Efficiency of a Prominent Place Based Policy.” American Economic Review 103 (2): 897-947.

Cameron, C.A., J.B. Gelbach, and D.L. Miller. 2008. "Bootstrap-based Improvements for Inference with Clustered Errors.” The Review of Economics and Statistics 90 (3): 414-27.

Campolieti, M., T. Fang, and M. Gunderson. 2003. "How Minimum Wages Affect SchoolingEmployment Outcomes in Canada, 1993-1999.” Journal of Labor Research 26 (3): 53345.

Canada Employment Insurance Commission, 1999 to 2002. Employment Insurance 1998/1999/2000/2001 Monitoring and Assessment Report.

Cahuc, P., S. Carcillo, and T. Le Barbanchon. 2014. "Do Hiring Credits Work in Recessions? Evidence from France.” IZA Discussion Paper 8330.

Card, D., R. Chetty, and A. Weber. 2007a. "Cash-on-hand and Competing Models of Intertemporal Behavior: New Evidence from the Labor Market.” The Quarterly Journal of Economics 122 (4): 1511-60.

--- 2007b. "The Spike at Benefit Exhaustion: Leaving the Unemployment System or Starting a New Job?” American Economic Review 97 (2): 113-18.

Chetty, R. 2006. “A General Formula for the Optimal Level of Social Insurance.” Journal of Public Economics 90 (10-11): 1879-1901.

Chetty, R. 2008. "Moral Hazard versus Liquidity and Optimal Unemployment Insurance.” Journal of Political Economy 116 (2): 173-234.

Congressional Budget Office. 2011. Testimony before the Committee on the Budget United States Senate. Statement of Douglas W. Elmendorf, Director: Policies for Increasing Economic Growth and Employment in 2012 and 2013. Technical Report. Washington: Congressional Budget Office.

Crepon, B., E. Duflo, M. Gurgand, R. Rathelot, and P. Zamora. 2012. "Do Labor Market Policies have Displacement Effects? Evidence from a Clustered Randomized Experiment.” NBER Working Paper 18597, December.

Dahlberg, M., and A. Forslund. 2005. "Direct Displacement Effects of Labour Market Programmes.” Scandinavian Journal of Economics 107 (3): 475-94. 
Davidson, R., and J.G. MacKinnon. 1999. “The Size Distortion of Bootstrap Tests.” Econometric Theory 15 (3): 361-76.

DiNardo, J.E., and D.S. Lee. 2011. Program Evaluation and Research Designs. $1^{\text {st }}$ ed., vol. 4A, chapter 5, 463-536. Elsevier.

Donald, S.G., and K. Lang. 2007. "Inference with Difference-in-differences and Other Panel Data.” The Review of Economics and Statistics 89 (2): 221-33.

Francesconi, M., and W. van der Klaauw. 2007. "The Socioeconomic Consequences of "Inwork” Benefit Reform for British Lone Mothers.” Journal of Human Resources XLII (1): $1-30$.

Friesen, J. 2002. "The Effect of Unemployment Insurance on Weekly Hours of Work in Canada.” Canadian Journal of Economics 35 (2): 363-84.

Green, D.A., and T. Sargent. 1998. "Unemployment Insurance and Job Durations: Seasonal and Non-seasonal Jobs.” Canadian Journal of Economics 31 (2): 247-78.

Green, D.A., and W. C. Riddell. 1997. "Qualifying for Unemployment Insurance: An Empirical Analysis.” Economic Journal 107 (440): 67-84.

Hernanz, V., J.F. Jimeno, and A.D. Kugler. 2003. "Employment Consequences of Restrictive Permanent Contracts: Evidence from Spanish Labour Market Reforms.” CEPR Discussion Papers 3724, January.

Imbens, G., and J. Wooldridge. 2009. "Recent Developments in the Econometrics of Program Evaluation,” Journal of Economic Literature 47(1): 5-86.

Khan, A.Q., and S.F. Lehrer. 2013. "The Impact of Social Networks on Labour Market Outcomes: New Evidence from Cape Breton.” Canadian Public Policy 39 (S1): 1-24.

Krueger, A.B., and B.D. Meyer. 2002. “Labor Supply Effects of Social Insurance.” In Handbook of Public Economics, edited by A. J. Auerbach and M. Feldstein, vol. 4, chapter 33, 2327-92. Elsevier.

Kuhn, P.J., and A. Sweetman. 1998. "Unemployment Insurance and Quits in Canada.” Canadian Journal of Economics 31 (3): 549-72.

Kuhn, P.J., and C. Riddell. 2010. “The Long-term Effects of Unemployment Insurance: Evidence from New Brunswick and Maine, 1940-1991.” Industrial and Labor Relations Review 63 (2): 183-204.

Landon, S. 1997. "High School Enrollment, Minimum Wages and Education Spending." Canadian Public Policy 23 (2): 141-63.

MacKinnon, J.G., and M.D. Webb. Forthcoming. "Wild Bootstrap Inference for Wildly Different Cluster Sizes.” Journal of Applied Econometrics.

Neumark, D. 2013. "Spurring Job Creation in Response to Severe Recessions: Reconsidering Hiring Credits.” Journal of Policy Analysis and Management 31 (1): 142-71.

Neumark, D., and D. Grijalva. 2013. "The Employment Effects of State Hiring Credits During and After the Great Recession.” NBER Working Paper 18928.

Neumark, D., and W. Wascher. 2004. "Minimum Wages, Labor Market Institutions, and Youth Employment: A Cross-national Analysis.” Industrial and Labor Relations Review 57 (2): 223-48.

O'Leary, C.J., P.T. Decke, and S.A. Wandner. 2005. “Cost-Effectiveness of Targeted Reemployment Bonuses.” Journal of Human Resources 40 (1): 270-79. 
Owyang, M.T., V.A. Ramey, and S. Zubairy. 2013. "Are Government Spending Multipliers Greater During Periods of Slack? Evidence from 20th Century Historical Data.” NBER Working Paper 18769, February.

Webb, M.D. 2014. "Reworking Wild Bootstrap Based Inference for Clustered Errors.” Working Paper 1315, Queen's University, Department of Economics, August. 
Figure 1a: Weeks Employed by Age Group, Males and Females

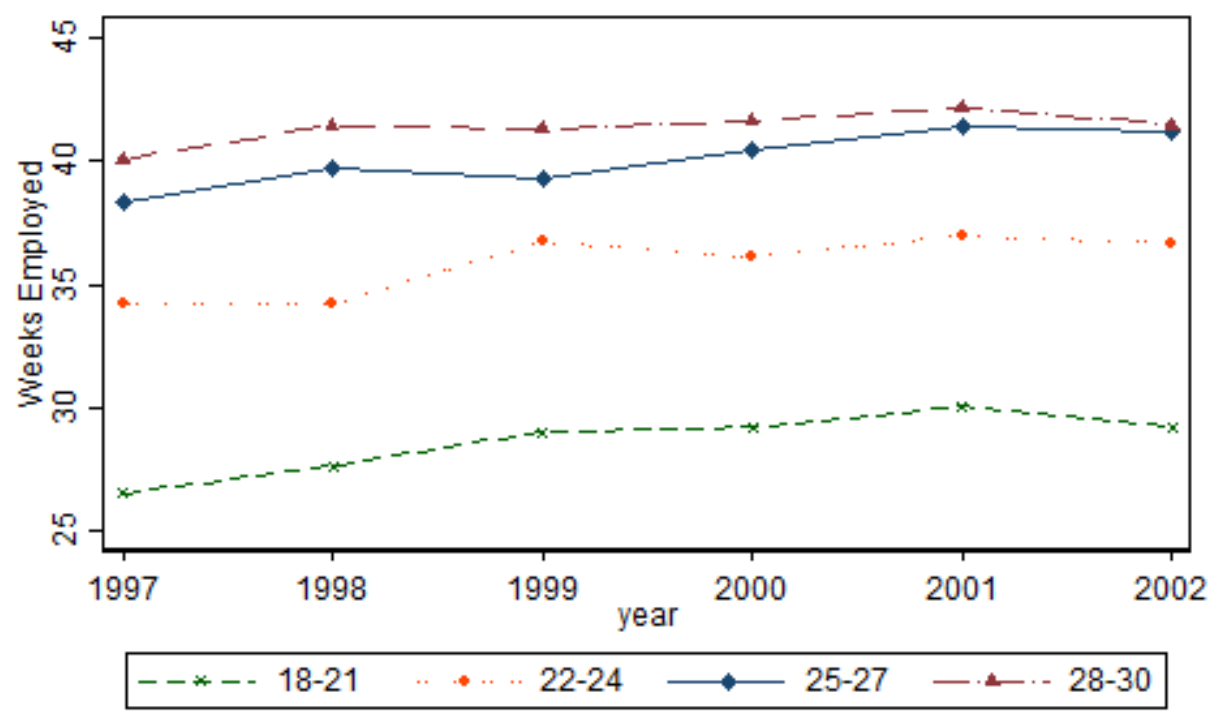

Source: 1997-2002 SLID microfile data. Individuals aged 18-30.

Figure 1b: Weeks Employed by Age Group, Females

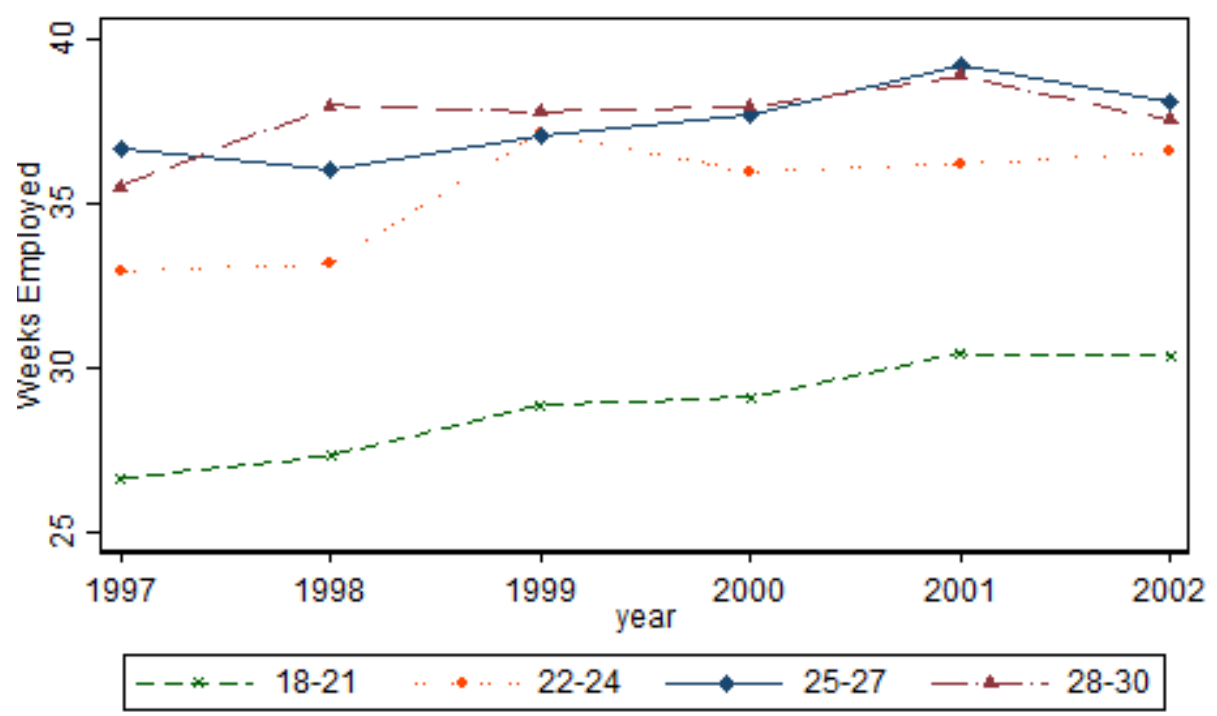

Source: 1997-2002 SLID microfile data. Individuals aged 18-30. 
Figure 1c: Weeks Employed by Age Group, Males

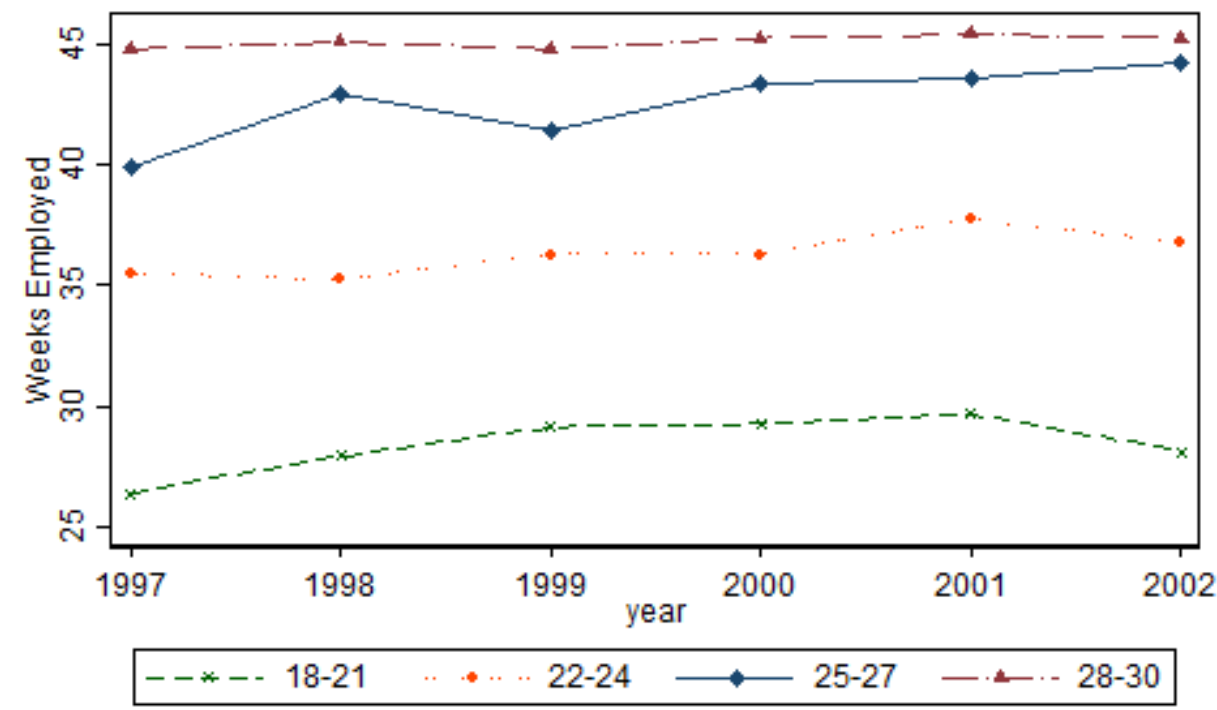

Source: 1997-2002 SLID microdata file. Individuals aged 18-30.

Figure 2: Weeks Not in the Labour Force by Age Group

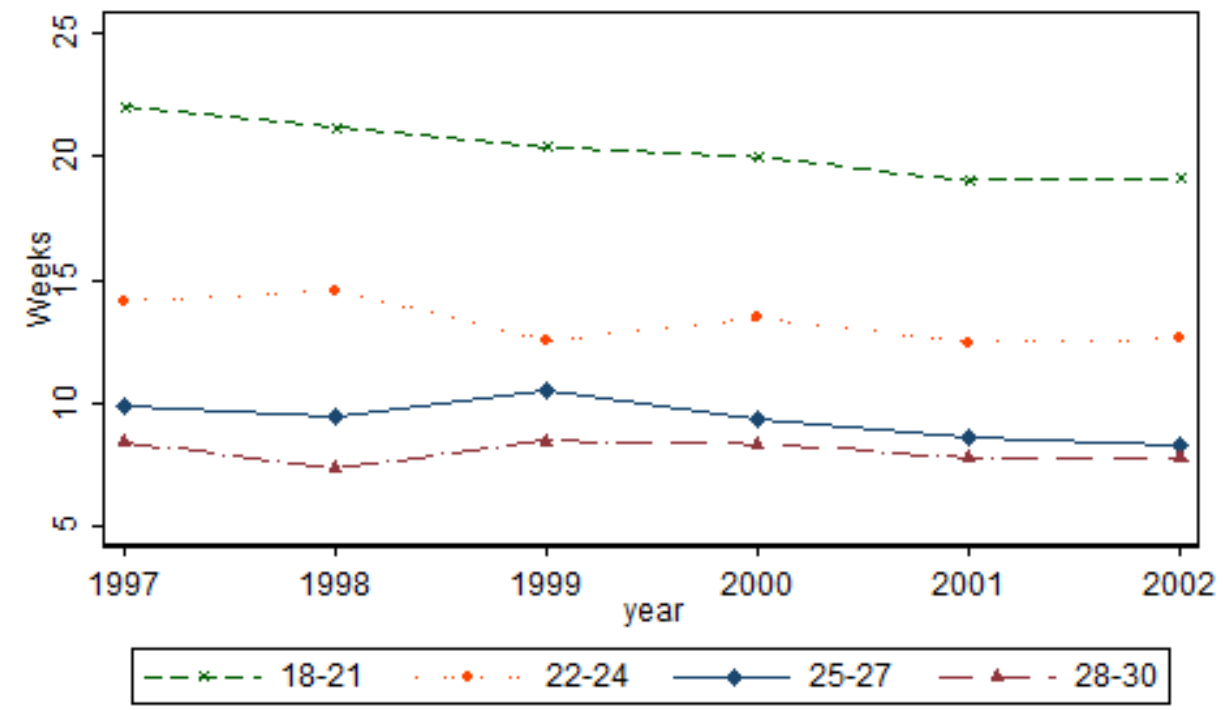

Source: 1997-2002 SLID microdata file. Individuals aged 18-30. 
Figure 3: Employment Rate by Age Group

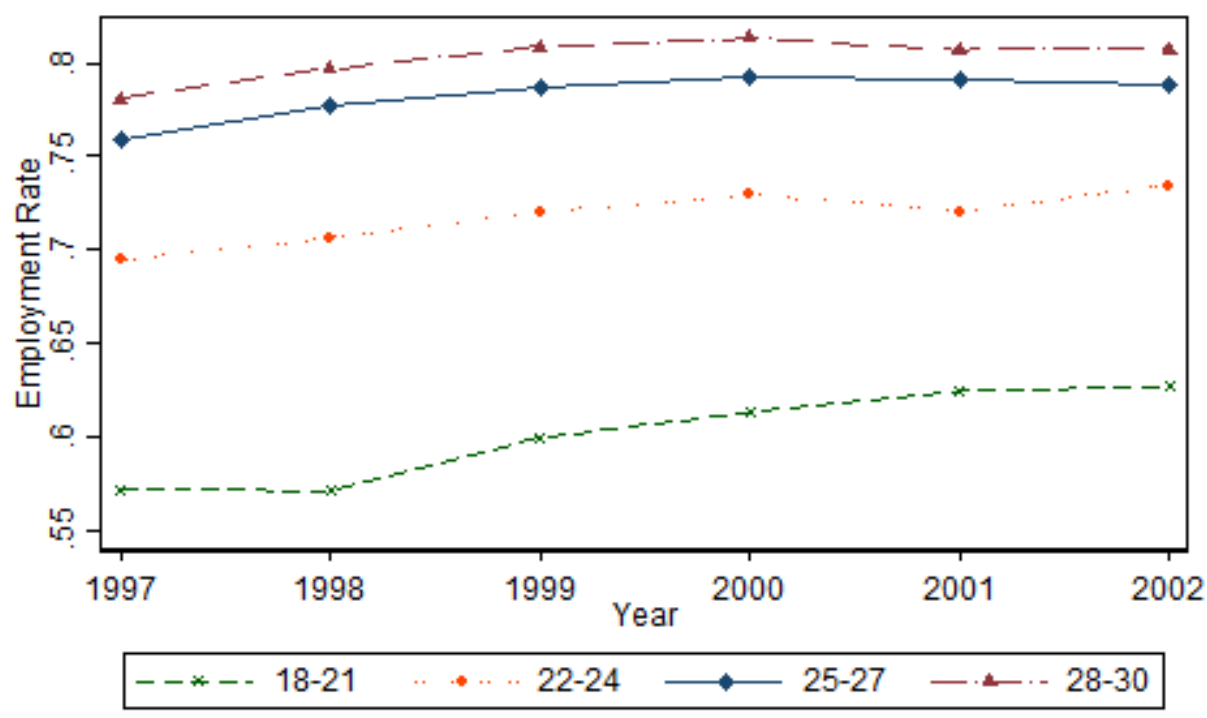

Source: 1997-2002 LFS microdata file. Individuals aged 18-30. 
Table 1

Variable Means and Sample Sizes 1997-98 and 1999-2000

\begin{tabular}{|c|c|c|c|c|c|c|c|c|}
\hline & \multicolumn{4}{|c|}{ 18-24 (Treated) } & \multicolumn{4}{|c|}{ 25-30 (Comparison) } \\
\hline & \multicolumn{2}{|c|}{ Before (97-98) } & \multicolumn{2}{|c|}{ During (99-00) } & \multicolumn{2}{|c|}{ Before (97-98) } & \multicolumn{2}{|c|}{ During (99-00) } \\
\hline & Mean & $\mathrm{N}$ & Mean & $N$ & Mean & $\mathrm{N}$ & Mean & $\mathrm{N}$ \\
\hline \multicolumn{9}{|l|}{ SLID } \\
\hline Annual Weeks Employed & 30.01 & 14,643 & 31.9 & 12,970 & 39.9 & 11,848 & 40.67 & 10,298 \\
\hline Annual Weeks Unemployed & 4.36 & 14,643 & 3.68 & 12,970 & 4.35 & 11,848 & 3.16 & 10,298 \\
\hline Annual Wks Not Lbr Force & 18.63 & 14,643 & 17.43 & 12,970 & 8.74 & 11,848 & 9.17 & 10,298 \\
\hline E Any Time in Year & 0.78 & 14,643 & 0.80 & 12,970 & 0.85 & 11,848 & 0.86 & 10,298 \\
\hline U Any Time in Year & 0.07 & 14,643 & 0.05 & 12,970 & 0.05 & 11,848 & 0.03 & 10,298 \\
\hline N Any Time in Year & 0.54 & 14,643 & 0.53 & 12,970 & 0.25 & 11,848 & 0.27 & 10,298 \\
\hline Total Annual Hours & 909 & 14,643 & 968 & 12,970 & 1508 & 11,848 & 1546 & 10,298 \\
\hline In(Annual Income) & 8.89 & 11,801 & 8.96 & 10,593 & 9.78 & 10,065 & 9.89 & 8,499 \\
\hline In(Average Wage) & 2.16 & 11,801 & 2.19 & 10,593 & 2.53 & 10,065 & 2.60 & 8,499 \\
\hline New Job & 0.52 & 12,024 & 0.54 & 10,789 & 0.26 & 10,466 & 0.30 & 8,965 \\
\hline Mostly Full-time work & 0.64 & 12,018 & 0.64 & 10,788 & 0.85 & 10,454 & 0.87 & 8,960 \\
\hline Full-time Student in Year & 0.66 & 14,622 & 0.65 & 12,946 & 0.21 & 11,832 & 0.22 & 10,277 \\
\hline \multicolumn{9}{|l|}{ LFS } \\
\hline Employed & 0.63 & 274,993 & 0.66 & 264,605 & 0.78 & 237,961 & 0.80 & 220,944 \\
\hline Unemployed & 0.10 & 274,993 & 0.09 & 264,605 & 0.08 & 237,961 & 0.06 & 220,944 \\
\hline Not in Labour Force & 0.27 & 274,993 & 0.26 & 264,605 & 0.14 & 237,961 & 0.14 & 220,944 \\
\hline Total Weekly Hours Worked & 30.29 & 168,306 & 30.83 & 170,900 & 35.83 & 180,862 & 36.19 & 172,578 \\
\hline In(Weekly Income) & 5.49 & 158,980 & 5.55 & 162,725 & 6.16 & 161,197 & 6.20 & 155,402 \\
\hline $\ln ($ Wage $)$ & 2.20 & 158,980 & 2.22 & 162,725 & 2.59 & 161,197 & 2.62 & 155,402 \\
\hline New Job & 0.04 & 168,829 & 0.08 & 171,700 & 0.02 & 181,090 & 0.03 & 172,841 \\
\hline Student & 0.37 & 276,730 & 0.37 & 266,192 & 0.09 & 240,447 & 0.09 & 223,081 \\
\hline
\end{tabular}


Table 2

Difference-in-Differences Employment Regressions

\begin{tabular}{|c|c|c|c|c|c|c|c|c|}
\hline & \multicolumn{6}{|c|}{ SLID } & \multirow{2}{*}{\multicolumn{2}{|c|}{$\frac{\text { LFS }}{\text { Employed in Week }}$}} \\
\hline & \multicolumn{3}{|c|}{ Weeks Employed in Year } & \multicolumn{3}{|c|}{ Employed Anytime in Year } & & \\
\hline & OLS & OLS & FE & OLS & OLS & FE & OLS & OLS \\
\hline Coefficient & 2.409 & 2.320 & 1.949 & 0.044 & 0.036 & 0.037 & 0.012 & 0.012 \\
\hline Hetero. Const. std err & 1.307 & 1.274 & 0.610 & 0.025 & 0.024 & 0.012 & 0.005 & 0.005 \\
\hline Clustered std err & 0.730 & 0.784 & 0.965 & 0.015 & 0.016 & 0.017 & 0.005 & 0.005 \\
\hline t-stat hetero & 1.844 & 1.821 & 3.195 & 1.748 & 1.487 & 3.041 & 2.426 & 2.405 \\
\hline t-stat cluster & 3.299 & 2.957 & 2.021 & 2.970 & 2.246 & 2.188 & 2.432 & 2.368 \\
\hline $\mathrm{p}$-value hetero $\mathrm{df}=\mathrm{N}-\mathrm{k}$ & 0.065 & 0.069 & 0.001 & 0.081 & 0.137 & 0.002 & 0.015 & 0.016 \\
\hline $\mathrm{p}$-value cluster $\mathrm{df}=\mathrm{N}-\mathrm{k}$ & 0.001 & 0.003 & 0.043 & 0.003 & 0.025 & 0.029 & 0.015 & 0.018 \\
\hline $\mathrm{p}$-value cluster $\mathrm{df}=\mathrm{G}-1$ & 0.005 & 0.010 & 0.062 & 0.010 & 0.040 & 0.045 & 0.028 & 0.032 \\
\hline $\mathrm{p}$-value cluster $\mathrm{df}=\mathrm{G}-2$ & 0.005 & 0.010 & 0.063 & 0.010 & 0.041 & 0.046 & 0.029 & 0.033 \\
\hline p-value wild bootstrap & 0.020 & 0.052 & 0.029 & 0.049 & 0.120 & 0.033 & 0.057 & 0.065 \\
\hline $\begin{array}{l}\text { p-value wild bootstrap } \\
\text { null imposed }\end{array}$ & 0.009 & 0.026 & 0.056 & 0.020 & 0.092 & 0.019 & 0.077 & 0.061 \\
\hline Bootstrap replications & 9999 & 9999 & 1499 & 9999 & 9999 & 1499 & 9999 & 9999 \\
\hline Number of clusters & 16 & 16 & 16 & 16 & 16 & 16 & 16 & 16 \\
\hline Observations & 49,759 & 49,759 & 49,759 & 49,759 & 49,759 & 49,759 & 985,148 & 985,148 \\
\hline Min cluster size & 928 & 928 & 928 & 928 & 928 & 928 & 20,452 & 20,452 \\
\hline Average cluster size & 3,445 & 3,445 & 3,445 & 3,445 & 3,445 & 3,445 & 69,165 & 69,165 \\
\hline Full set of controls & No & Yes & Yes & No & Yes & Yes & No & Yes \\
\hline
\end{tabular}

Notes: All regressions include sets of indicator variables for individual's age and year of birth, and the survey year (and month for the LFS only). All regressions include an indicator variable for those individuals who were 24 in 1999. In both LFS and SLID regressions when "Controls=Yes" additional indicators for province of residence and urban residence are added, as well as, for the SLID only, indicators for visible minority and immigrant status. The Fixed Effects (FE) regressions necessarily omit time invariant variables such as year of birth and immigration status. The "heteroskedastic consistent standard errors" for the FE regressions and the associated tstat and p-value are estimated clustering on the individual, whereas the estimates for the "heteroskedastic consistent standard errors" for the OLS regressions are not clustered. 
Table 3

Difference-in-Differences Estimates for 18-24 Year Olds, 25-30 as Comparison Group

\begin{tabular}{|c|c|c|c|c|c|c|}
\hline & \multicolumn{2}{|c|}{ All } & \multicolumn{2}{|c|}{ Female } & \multicolumn{2}{|c|}{ Male } \\
\hline & Coef & $\begin{array}{l}\text { Wild } \\
\text { p-value }\end{array}$ & Coef & $\begin{array}{l}\text { Wild } \\
p \text {-value }\end{array}$ & Coef & $\begin{array}{l}\text { Wild } \\
p \text {-value }\end{array}$ \\
\hline \multicolumn{7}{|l|}{ SLID } \\
\hline Annual Weeks Employed & 2.320 & 0.019 & 1.028 & 0.504 & 3.602 & 0.007 \\
\hline Annual Weeks Unemployed & 0.059 & 0.851 & 0.714 & 0.209 & -0.562 & 0.545 \\
\hline Annual Wks Not Lbr Force & -2.379 & 0.008 & -1.742 & 0.355 & -3.040 & 0.007 \\
\hline E Any Time in Year & 0.036 & 0.113 & 0.026 & 0.559 & 0.048 & 0.031 \\
\hline U Any Time in Year & -0.005 & 0.736 & 0.024 & 0.248 & -0.034 & 0.171 \\
\hline N Any Time in Year & -0.055 & 0.016 & -0.011 & 0.677 & -0.100 & 0.037 \\
\hline Total Annual Hours & 22.888 & 0.480 & 14.974 & 0.713 & 34.657 & 0.345 \\
\hline In(Annual Income) & -0.073 & 0.108 & -0.060 & 0.481 & -0.090 & 0.056 \\
\hline In(Average Wage) & -0.038 & 0.017 & -0.049 & 0.185 & -0.027 & 0.337 \\
\hline New Job & -0.006 & 0.880 & 0.050 & 0.292 & -0.049 & 0.393 \\
\hline Mostly Full-time work & -0.042 & 0.021 & -0.002 & 0.972 & -0.077 & 0.024 \\
\hline Full-time Student in Year & -0.028 & 0.248 & -0.013 & 0.591 & -0.044 & 0.152 \\
\hline \multicolumn{7}{|l|}{ LFS } \\
\hline Employed - binary & 0.012 & 0.056 & 0.002 & 0.847 & 0.022 & 0.056 \\
\hline Unemployed - binary & 0.004 & 0.440 & 0.005 & 0.539 & 0.002 & 0.795 \\
\hline Not in Labour Force - binary & -0.015 & 0.007 & -0.007 & 0.524 & -0.024 & 0.011 \\
\hline Total Weekly Hours Worked & -0.113 & 0.605 & -0.309 & 0.269 & 0.109 & 0.807 \\
\hline In(Weekly Income) & -0.003 & 0.701 & 0.004 & 0.787 & -0.008 & 0.557 \\
\hline In(Wage) & -0.002 & 0.759 & 0.001 & 0.916 & -0.004 & 0.788 \\
\hline New Job & -0.028 & 0.007 & -0.033 & 0.001 & -0.023 & 0.100 \\
\hline Student & 0.005 & 0.520 & 0.013 & 0.184 & -0.002 & 0.916 \\
\hline
\end{tabular}

Notes: Wild p-values are based on 1499 bootstrap replications with the null hypothesis that the coefficient equals zero imposed. All regressions have the full set of control variables listed in Table 2. 
Table 4A

Difference-in-Differences with 28-30 Year Olds as the Comparison Group, Males

\begin{tabular}{|c|c|c|c|c|c|c|}
\hline & $\begin{array}{l}18-21 \\
\text { Coeff }\end{array}$ & $\begin{array}{l}\text { Wild } \\
\text { p-value }\end{array}$ & $\begin{array}{l}22-24 \\
\text { Coeff }\end{array}$ & $\begin{array}{l}\text { Wild } \\
\text { p-value }\end{array}$ & $\begin{array}{l}25-27 \\
\text { Coeff }\end{array}$ & $\begin{array}{l}\text { Wild } \\
\text { p-value }\end{array}$ \\
\hline \multicolumn{7}{|l|}{ SLID } \\
\hline Annual Weeks Employed & 5.911 & 0.036 & 3.850 & 0.180 & 0.396 & 0.793 \\
\hline Annual Weeks Unemployed & 0.852 & 0.425 & -1.224 & 0.160 & -1.026 & 0.219 \\
\hline Annual Wks Not Lbr Force & -6.763 & 0.036 & -2.626 & 0.249 & 0.629 & 0.529 \\
\hline E Any Time in Year & 0.097 & 0.027 & 0.037 & 0.328 & -0.016 & 0.523 \\
\hline U Any Time in Year & -0.045 & 0.087 & -0.016 & 0.037 & 0.005 & 0.395 \\
\hline N Any Time in Year & -0.113 & 0.112 & -0.101 & 0.009 & 0.021 & 0.197 \\
\hline Total Annual Hours & 243.228 & 0.091 & 141.221 & 0.293 & 32.132 & 0.631 \\
\hline Ln(Annual Income) & 0.292 & 0.093 & 0.131 & 0.304 & 0.134 & 0.431 \\
\hline Ln(Average Wage) & 0.001 & 0.971 & 0.012 & 0.921 & 0.044 & 0.719 \\
\hline New Job & -0.035 & 0.303 & -0.055 & 0.157 & -0.016 & 0.613 \\
\hline Mostly Full-time work & 0.095 & 0.036 & 0.031 & 0.572 & 0.008 & 0.921 \\
\hline Full-time Student in Year & -0.159 & 0.024 & -0.104 & 0.035 & -0.059 & 0.027 \\
\hline \multicolumn{7}{|l|}{ LFS } \\
\hline Employed - binary & 0.083 & 0.051 & 0.047 & 0.068 & 0.015 & 0.182 \\
\hline Unemployed - binary & 0.003 & 0.741 & 0.007 & 0.553 & 0.000 & 0.900 \\
\hline Not in the labour force - binary & -0.086 & 0.011 & -0.054 & 0.063 & -0.015 & 0.057 \\
\hline Hours worked actual total & 5.018 & 0.046 & 2.536 & 0.074 & 0.342 & 0.222 \\
\hline Ln(income) & 0.325 & 0.017 & 0.141 & 0.034 & 0.059 & 0.057 \\
\hline Ln(wage) & 0.097 & 0.046 & 0.051 & 0.034 & 0.039 & 0.063 \\
\hline New job in ref week & 0.000 & 0.934 & -0.006 & 0.615 & -0.010 & 0.541 \\
\hline Student & -0.135 & 0.028 & -0.067 & 0.057 & -0.019 & 0.046 \\
\hline
\end{tabular}

Notes: Wild p-values are based on 1499 bootstrap replications with the null hypothesis that the coefficient equals zero imposed. All regressions have the full set of control variables listed in Table 2. 
Table 4B

Difference-in-Differences with 28-30 Year Olds as the Comparison Group, Females

\begin{tabular}{|c|c|c|c|c|c|c|}
\hline & $\begin{array}{c}18-21 \\
\text { Coeff } \\
\end{array}$ & $\begin{array}{c}\text { Wild } \\
\text { p-value }\end{array}$ & $\begin{array}{c}22-24 \\
\text { Coeff }\end{array}$ & $\begin{array}{c}\text { Wild } \\
\text { p-value }\end{array}$ & $\begin{array}{l}25-27 \\
\text { Coeff }\end{array}$ & $\begin{array}{l}\text { Wild } \\
\text { p-value }\end{array}$ \\
\hline \multicolumn{7}{|l|}{ SLID } \\
\hline Annual Weeks Employed & 4.956 & 0.004 & 3.505 & 0.049 & -0.291 & 0.424 \\
\hline Annual Weeks Unemployed & 2.303 & 0.100 & 1.393 & 0.132 & 1.410 & 0.372 \\
\hline Annual Wks Not Lbr Force & -7.259 & 0.015 & -4.898 & 0.059 & -1.118 & 0.268 \\
\hline E Any Time in Year & 0.070 & 0.021 & 0.028 & 0.437 & -0.015 & 0.712 \\
\hline U Any Time in Year & 0.010 & 0.667 & 0.027 & 0.332 & 0.010 & 0.967 \\
\hline N Any Time in Year & -0.139 & 0.047 & -0.114 & 0.061 & -0.020 & 0.581 \\
\hline Total Annual Hours & 248.932 & 0.007 & 203.410 & 0.039 & 28.274 & 0.309 \\
\hline In(Annual Income) & 0.366 & 0.029 & 0.194 & 0.200 & 0.030 & 0.844 \\
\hline In(Average Wage) & -0.018 & 0.329 & 0.028 & 0.257 & 0.020 & 0.453 \\
\hline New Job & 0.010 & 0.951 & -0.080 & 0.331 & -0.053 & 0.567 \\
\hline Mostly Full-time work & 0.133 & 0.017 & 0.028 & 0.289 & 0.017 & 0.304 \\
\hline Full-time Student in Year & -0.120 & 0.028 & -0.163 & 0.097 & -0.054 & 0.015 \\
\hline \multicolumn{7}{|l|}{ LFS } \\
\hline Employed - binary & 0.081 & 0.040 & 0.046 & 0.046 & 0.022 & 0.108 \\
\hline Unemployed - binary & -0.014 & 0.160 & -0.014 & 0.256 & -0.011 & 0.336 \\
\hline Not in the labour force - binary & -0.067 & 0.085 & -0.032 & 0.046 & -0.011 & 0.302 \\
\hline Hours worked actual total & 4.446 & 0.006 & 2.523 & 0.028 & 0.876 & 0.011 \\
\hline Ln(income) & 0.320 & 0.046 & 0.206 & 0.057 & 0.083 & 0.017 \\
\hline Ln(wage) & 0.079 & 0.074 & 0.068 & 0.040 & 0.033 & 0.040 \\
\hline New job in ref week & -0.005 & 0.684 & -0.006 & 0.644 & -0.005 & 0.741 \\
\hline Student & -0.123 & 0.017 & -0.071 & 0.057 & -0.024 & 0.011 \\
\hline
\end{tabular}

Notes: Wild p-values are based on 1499 bootstrap replications with the null hypothesis that the coefficient equals zero imposed. All regressions have the full set of control variables listed in Table 2. 
Table 5

Falsification Test Using Data From 2002-2005

\begin{tabular}{|c|c|c|c|c|c|c|}
\hline \multirow[b]{2}{*}{ SLID } & \multicolumn{2}{|c|}{$\begin{array}{l}\text { All } \\
\text { Wild } \\
\text { p-value }\end{array}$} & \multicolumn{2}{|c|}{$\begin{array}{l}\text { Male } \\
\text { Wild } \\
\text { p-value }\end{array}$} & Coef & $\begin{array}{l}\text { Wild } \\
\text { p-value }\end{array}$ \\
\hline & & & & & & \\
\hline Annual Weeks Employed & -0.09 & 0.979 & 1.186 & 0.388 & -1.336 & 0.439 \\
\hline Annual Weeks Unemployed & 0.526 & 0.329 & 0.895 & 0.335 & 0.111 & 0.855 \\
\hline Annual Wks Not Lbr Force & -0.437 & 0.687 & -2.082 & 0.156 & 1.224 & 0.363 \\
\hline E Any Time in Year & -0.022 & 0.387 & -0.003 & 0.951 & -0.038 & 0.241 \\
\hline U Any Time in Year & 0.021 & 0.051 & 0.015 & 0.547 & 0.026 & 0.167 \\
\hline N Any Time in Year & -0.025 & 0.585 & -0.078 & 0.093 & 0.03 & 0.487 \\
\hline Total Annual Hours & 9.816 & 0.759 & 34.133 & 0.383 & -14.198 & 0.803 \\
\hline In(Annual Income) & 0.021 & 0.772 & 0.016 & 0.836 & 0.032 & 0.721 \\
\hline In(Average Wage) & -0.007 & 0.693 & 0.002 & 0.957 & -0.015 & 0.592 \\
\hline New Job & -0.035 & 0.299 & -0.042 & 0.271 & -0.029 & 0.583 \\
\hline Mostly Full-time work & -0.004 & 0.813 & -0.03 & 0.152 & 0.022 & 0.431 \\
\hline Full-time Student in Year & 0.008 & 0.757 & 0.038 & 0.073 & -0.022 & 0.557 \\
\hline \multicolumn{7}{|l|}{ LFS } \\
\hline Employed & 0.003 & 0.805 & -0.013 & 0.137 & 0.016 & 0.239 \\
\hline Unemployed & -0.009 & 0.088 & 0.001 & 0.789 & -0.018 & 0.011 \\
\hline Not in Labour Force & 0.006 & 0.368 & 0.011 & 0.083 & 0.002 & 0.843 \\
\hline Total Weekly Hours Worked & 0.233 & 0.488 & 0.839 & 0.112 & -0.337 & 0.507 \\
\hline In(Weekly Income) & -0.007 & 0.684 & 0.012 & 0.588 & -0.026 & 0.107 \\
\hline In(Wage) & -0.016 & 0.208 & -0.013 & 0.353 & -0.019 & 0.131 \\
\hline New Job & 0.004 & 0.56 & -0.002 & 0.837 & 0.009 & 0.339 \\
\hline Student & 0.015 & 0.105 & 0.003 & 0.756 & 0.026 & 0.023 \\
\hline
\end{tabular}

Notes: Wild p-values are based on 1499 bootstrap replications with the null hypothesis that the coefficient equals zero imposed. All regressions have the full set of control variables listed in Table 2. 


\section{Data Appendix A}

The data used in the paper comes from two sources, the Labour Force Survey (LFS) and the Survey of Labour and Income Dynamics (SLID). The datasets used were constructed to maximize the number of observations for both the treatment and comparison groups. This means that we took observations from a number of different panels for every year of interest. The sample was based on the reference year, and the age of individuals in the reference year.

The bulk of the analysis uses observations from individuals aged 18-30 years old in years from 1997-2000. The SLID surveys individuals in panels, with a panel lasting for six years, and a new panel introduced every three years. In the SLID this means that individuals from Panel 1 are in the sample in 1997, individuals from Panel 2 are in the sample for all years, while individuals from Panel 3 are in the sample for 1999 and 2000. While the SLID asks labour market questions to individuals aged 16 to 70, we restrict the sample to those who were 18-30 years old at any point in a reference year.

The LFS surveys individuals in panels for six months. A new panel is introduced every month, so $1 / 6$ th of the sample is new every month. We selected all months in 1997-2000 for our sample. This involved using the tail end of some panels in the beginning of 1997 and the early part of some panels at the end of 2000 . While the LFS covers the population 15 years of age and over, we restrict the sample to those 18-30 in a reference month.

Within the SLID, we used information for all jobs for the weeks employed and annual hours variables, whereas we used hours weighted averages for the annual income and average wage. Within the LFS total hours is from all jobs.

The falsification exercise presented in Table 5 similarly uses all available information for individuals aged 18-30 in 2002-2005 in either the SLID or the LFS. In the SLID this means that individuals from Panel 3 are included for 2002-2004, individuals from Panel 4 are included from 2002-2005, and individuals from Panel 5 are included in 2005. 